\title{
Analysing Road Traffic Situation in Lilongwe: An Agent Based Modelling (ABM) Approach
}

\author{
Khetwayo B Sibale, Kondwani G Munthali
}

Computer Science Department, Chancellor College, University of Malawi

\begin{abstract}
A 15, $451 \mathrm{~km}$ road network forms the main mode of transport for Malawi with $26 \%$ paved. With increasing number of vehicles and elongated travel times during rush hour the study analysed the traffic situation on the M1 road between Mchinji and Area 18 roundabouts in Lilongwe City using an agent-based model (ABM).

* Corresponding Authar email:

msc-inf-05-17@cc.ac.mw

Article History

Received: 20 October 2020

Revised: 13 January 2021

Accepted: 17 February 2021

Published: 07 March 2021

Student(s)

- Khetwayo B Sibale

Academic Year: 2019-20

Course Level: Master

Course Name: M.Sc. (Informatics)

Course year: Final Year

Mentor(s)

- $\quad$ Dr. Kondwani G Munthali

The methodology used game theory's traffic grip model to analyse traffic flow by controlling traffic variables such as lights, speed limits and the number of vehicles. Each intersection was treated as non-cooperative game where each agent tried to minimize its queue resulting into $\mathrm{Q}-\mathrm{Nash}$ 's equilibrium as the solution. The ABM tested the empirical relationships of traffic flow parameters in terms of density, flow, acceleration, deceleration, speed, time lost in traffic congestion and fuel consumption. The model was calibrated using traffic data collected through observing 1,312 vehicles sampled against 24,977 . The observation results from the road junctions reveal that on average, a vehicle takes 20 mins 18 seconds, 37 minutes 6 seconds, 44 minutes 21 seconds and 58 minutes 53 seconds to exit Chitukuko, Bwandilo, Chilambula roads and Area 18 roundabout respectively upon entering the M1 at Mchinji roundabout. This data was then used to calibrate the business-as-usual model for the peak hour scenario for the road junctions. The model results show that a selected vehicle entering Chitukuko junction travels at an average speed of $22.60 \mathrm{~km} / \mathrm{hr}$, until it exits that junction. On average the selected motorists spend $2.52 \mathrm{l} / \mathrm{km}$ with a traffic density of $72 \mathrm{v} / \mathrm{km}$. If dualized average speeds improved to $41.54 \mathrm{~km} / \mathrm{hr}$ while the traffic density declined to $54.42 \mathrm{v} / \mathrm{km}$, saving motorists MK 3,921,624.00 annually. The predictive model of the dual carriage informed that by 2021, commuters will spend MK 5,187,168 on fuel more than single-lane business as usual scenario of 2019 .
\end{abstract}

Keywords: Agent-based modelling, Traffic model, Fuel consumption, Road construction. 


\section{$1 \quad$ Introduction}

Increased urbanization and population growth tend to induce increase in number of vehicles thereby exerting pressure on traffic movements. With the continued growth of motor vehicles in Lilongwe city, the city roads experience traffic congestion and traffic bottlenecks at peak hours. Despite government efforts to construct new roads for the city, traffic congestion is still a problem for Lilongwe inhabitants. Again, the stopping and starting in traffic jams burns fuel at a higher rate than the smooth rate of travel on the open highway. This increase in fuel consumption, costs commuters' additional money for fuel and it contributes to the number of emissions released by the vehicles. These emissions create air pollution hence contributing to global warming. $74 \%$ of roads in Malawi are not paved and the paved ones, are not only few but are usually small in size, poorly constructed, and lack a number of traffic components. In Lilongwe, this is evidenced by narrow mostly single lane roads, non-operating traffic lights, lack of pavements and unavailability of flyovers/subways among others. Again, with reduced cost of used vehicles, the vehicle population has been growing rapidly and is projected to continue growing (see Figure 1). This has since resulted into large volumes of cars competing for the small roads thereby causing traffic congestion especially during rush hours.

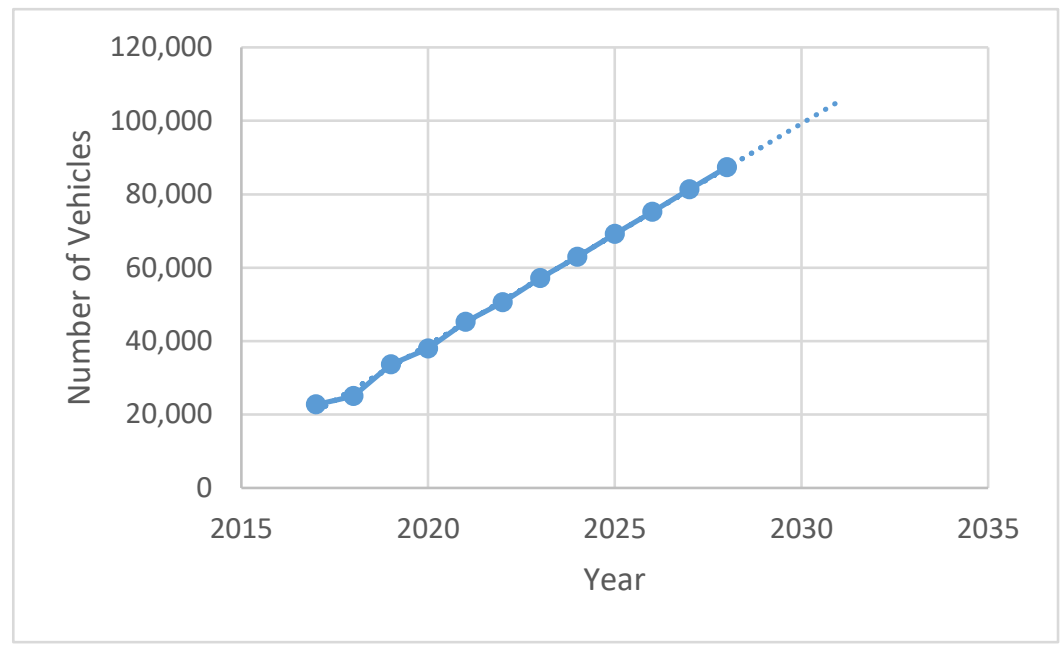

Figure 1: Lilongwe Vehicle Population growth

Wang et al. defines a traffic index as a composite indicator that includes estimation of time consumed in traffic commuting to work, dissatisfaction, and overall inefficiencies in the traffic system [1]. Congestion is strongly correlated with increased emission rates as it is associated with low speeds and stop and go conditions which result into increased travel times, increased energy usage and vehicular emissions [2]. Thus, the economic cost for traffic congestion is huge. For instance, according to INRIX data, Americans lost an average of 97 hours a year due to congestion, costing them nearly USD87 billion in 2018, an average of USD1,348 per driver [3]. A report by the transport directorate in Republic of South Africa in 2019 reported that traffic congestion in Cape Town costed the City about USD1.8 million [4].

Lilongwe, the capital city of Malawi with an estimated population of 1, 637, 583 [5], is an important economic and transportation hub for Malawi. The M1 Junctions that connect with other secondary roads, suburbs and markets, are its major highlights for traffic congestion. In this study, however, we focused on a $3.4 \mathrm{~km} \mathrm{M1} \mathrm{stretch} \mathrm{between} \mathrm{Mchinji} \mathrm{and} \mathrm{Area} 18$ roundabouts covering the following junctions: Chitukuko M1 junction, Bwandilo-Chilambula M1 junction and Chilambula M1 junction (see Figure 2). Despite efforts by the Government of Malawi to reduce congestion by constructing more roads in the city, such as the bypass connecting the Blantyre-Lilongwe (M1) Road, and the Lilongwe-Mchinji (M12) road at Bunda Turnoff and Kaunda Road, respectively, through the Southern zone of the City, traffic congestion is still a problem for Lilongwe inhabitants. 
The objective of the study weas thus to analyse the traffic situation in Lilongwe by quantifying macroscopic traffic characteristics of density, average speed, and fuel consumption both in terms of litres and cost on this stretch using an agent-based model (ABM). Specifically, the study did not only investigate the current situation in the selected roads of Lilongwe at peak hours but also modelled traffic congestion in the selected roads. The rest of the of the paper is organised in that we present the agent-based model concepts, data and methods used before discussing the theoretical framework. We then discuss the results and then conclude.

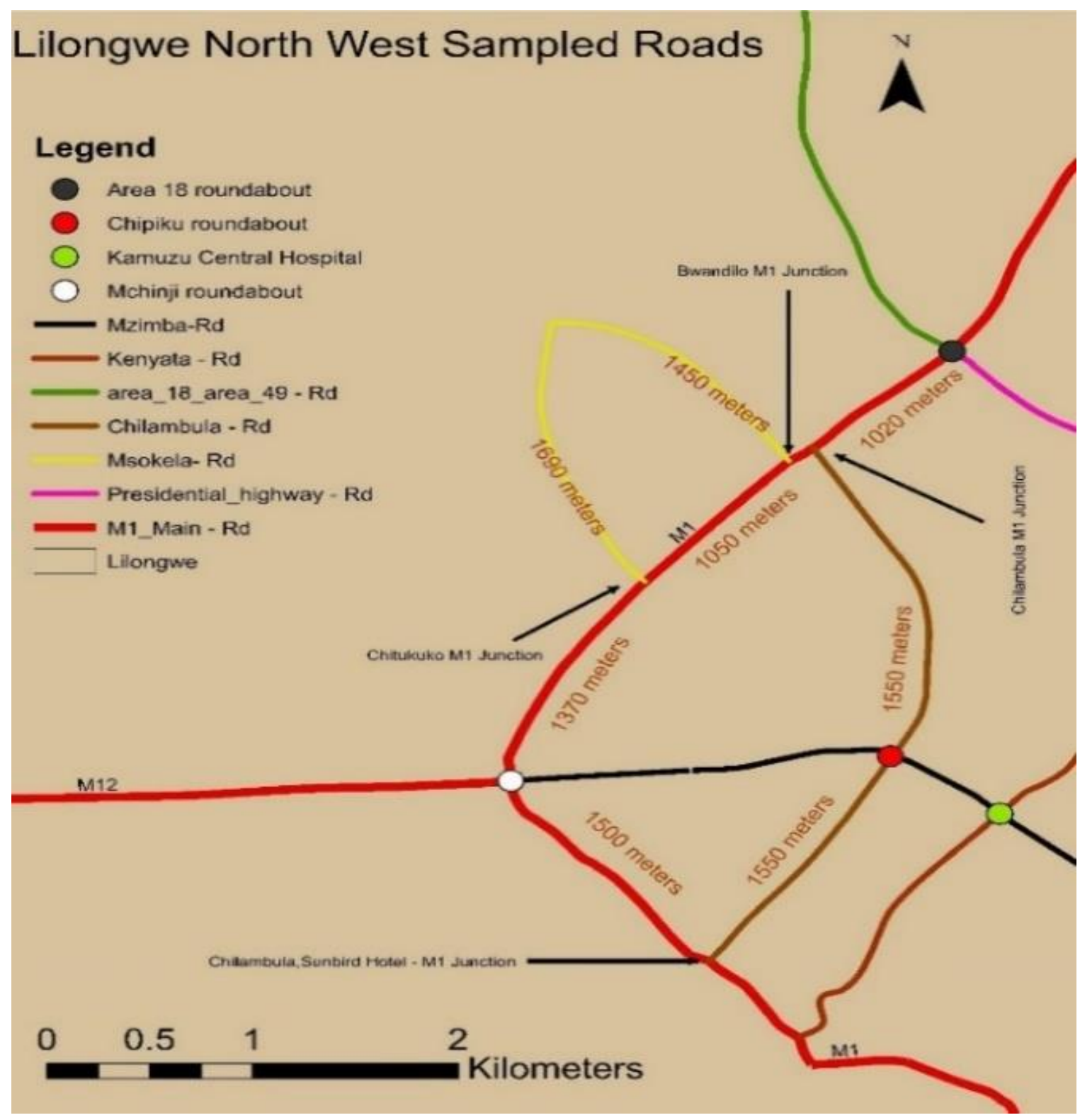

Figure 2: Study Area

\section{$2 \quad$ Agent-based modelling}

An agent is a computer system that is situated in some environment and is capable of autonomous action in the environment in order to meet its design objectives [6]. Thus, agent-based modelling captures real-life social systems on a computer by replicating the behaviours of heterogeneous participants and modelling the interactions between them. Just as human beings in the real-world traffic situation have plans, goals and aims when carrying out specific objectives, agents have plans, goals and aims. Thus, agents make plans of actions to perform and aim to achieve their goals through those plans. Murphy et al. further outlines that agents can receive sensory input from their environment, which then affect their actions that influence their 
environment, usually have a set of predefined actions to perform where each action aims to affect their environment [7]. They are also able to communicate with each other, allowing them to cooperate, negotiate and coordinate their actions [7].

There have been extensive studies on the use of ABM to solve complex social phenomenon globally. Wang et al. used $\mathrm{ABM}$ to examine the environmental consequences and economic impacts of water resource shortages under variant economic policies in Dianchi Lake Basin in China [8]. A complex system model was proposed to simulate the impact of alternative economic policies on water use and pricing. It generated a macroscopic socio-economic-environment system based on the resultant policy regulation to simulate the microcosmic agents' behaviour and macroscopic implementation effect [8]. To achieve their policy plan targets, the model proposed that water price and sewage treatment fee for residents needed to be raised to 3.23 CNY/m3 and $1.50 \mathrm{CNY} / \mathrm{m} 3$, respectively [8]. The model also proposed that water price and sewage treatment fee for industrial should be raised to $4.99 \mathrm{CNY} / \mathrm{m} 3$ and $2.25 \mathrm{CNY} / \mathrm{m} 3$ under the situation of a comprehensive adjustment of the industrial structure and policy [8]. In diffusion, Kuusemäe et al. simulated seed dispersal and losses in Odense Fjord, Denmark [9]. The model handled two ways of seed dispersal: i) seeds dropped in eelgrass beds and transported by hydrodynamic forces along the seabed ii) seeds released by rafting shoots [9]. The model estimated that approximately $92 \%$ of the seeds would be retained in the Odense Fjord, while only $5.0 \%$ of the seeds ended up in areas supporting seedling establishment [9]. In the context of Malawi, Munthali used ABM to derive understanding of the underlying causes of deforestation in Dzalanyama forest and estimated the future of forest cover loss [10]. The deforestation trends for Dzalanyama forest reserve were simulated over a 40-year period beginning the year 1990. In the business-as-usual scenario 12, 207 ha of forest were simulated as lost against 13, 639 ha observed in 2000. The quantities accumulated to 19,459 ha simulated against 22,031 ha observed by the year 2010. Munthali [10] further predicted that the south-eastern part of the forest reserve would have lost almost all its forest cover by 2030, with the deeper and further western side maintaining most of its forest cover.

In all these studies, the benefits of ABM, as outlined by Lindkvist $e t$ al. over other modelling techniques is their capability to capture emergent phenomena that result from the interactions of individual entities [11]. Entities are not reduced to the system's parts: the whole is more than the sum of its parts because of the interactions between the parts; an emergent phenomenon can have properties that are decoupled from the properties of the part [12]. 'Emergence' is a phenomenon at one level that constitutes the units of interaction, or drivers of change, at a higher level [13]. A good example of emergent phenomena is traffic congestion, which results from the behaviour of and interactions between individual vehicle drivers, and their surroundings. This characteristic of emergent phenomena makes them difficult to understand and predict since emergent phenomena can be counterintuitive. ABM is, by its very nature, the canonical approach to modelling emergent phenomena since one model can simulate the behaviour of the system's constituent units (the agents) and their interactions, capturing emergence from the bottom up when the simulation is running [14].

\section{$3 \quad$ Research Methodology}

\subsection{Methods and data}

The study employed both quantitative and qualitative methods to collect data. Between 8th January 2019 and 5th March 2019, the authors observed and collected the following data: total number of vehicles entering a junction, total number of vehicles in Lilongwe city, number of operating and available traffic lights at a junction, number of vehicles making a left or right turn at a junction, and amount of time it took a vehicle to exit a particular junction. The data was collected for normal traffic flow from 10:00 to 14:00hrs and peak hour flow from 17:00 to 20:00hrs. A total number of 1,312 and 324 vehicles were observed at rush hour and normal traffic respectively. For each vehicle observed, the vehicle registration number was masked, the time the vehicle entered Mchinji M1 roundabout and the time it exited any of the Chitukuko, 
Bwandilo-Chilambula junctions or Area 18 roundabout were collected. The probability of a vehicle making a left or right turn on junctions was denoted as:

$$
P=m / c * 100 .
$$

Where $P$ is the probability; $m$ is the maximum number of vehicles making the turn; $c$ is the maximum number of vehicles in a road segment at a specific time. This data was then used to calibrate and validate a business as usual (BAU), dual carriage empirical and predictive scenarios for 2019, 2020 and 2021 respectively in NetLogo. Traffic grid patterns represented the M1 junctions, traffic lights operation and car movements in relation to traffic flow parameters based on the observed data for the BAU and projections for the predictive scenarios. NetLogo is an agent-based modelling environment designed for simulating complex natural and social phenomena. Written in Java and Scala, it is a cross-platform freeware with a large friendly user group. It enables the user to model any number of agents in a variable-size environment using a simple programming language derived from Logo. Wilensky provides a detailed description of NetLogo [15].

Traffic flow is analysed using aggregated macroscopic properties of multiple vehicles in a traffic stream [16]. While there are several of them, this study focused on traffic density, average speeds and fuel consumption. Traffic density is defined as the number of vehicles (volume of traffic) occupying a unit length of roadway at any instance expressed as:

$$
k=n / x
$$

Where $n$ is the number of vehicles in the section of a road, $x$ is the length of the section of the road, and $k$ is the density expressed in terms of vehicles $/ \mathrm{km}$. Average speed is the second macroscopic property concerning multiple rather than individual vehicles. This is the average of vehicle speeds weighted according to how long they remain on the section of road. The average speed, denoted by $u_{t}$, is thus defined as:

$$
u_{t}=\frac{\sum_{i=1}^{n}\left(\mu_{i}\right)}{n}
$$

Where $n$ is the number of vehicles, and $\mu_{i}$ is the speed of an individual vehicle $i$ [17]. In addition to the mean speed, maximum and minimum speeds of vehicles at road sections were also observed. The simulation also observed a selected vehicle's speed, traffic density and flow, and fuel consumed as the vehicle exited through a particular junction. In this case, fuel consumption was the amount of fuel consumed in driving a given distance, expressed in litres per 100 kilometres and was used as a direct measure of volumetric fuel savings. It is denoted as:

$$
F C=l / d
$$

Where $l$ is fuel in litres and $d$ is distance in kilometres. Understanding that $F C$ is constant (assumed as 1 for model simplicity) for each individual vehicle (all factors constant and at any given time), the amount of fuel spent $l$ is, thus, directly proportional to the speed $(S)$ and time $(t)$. Therefore, the number of litres spent on a road patch was observed as $L$ given by:

$$
L=S . t
$$

A qualitative observation was also conducted to understand traffic monitoring, control, management, enforcement and forecasting to help in the model calibration and validation.

\subsection{Modelling}

The modelling then followed the conceptual model as shown in Figure 3. The traffic grid model was built to represent the M1 road junction roads, traffic lights operation and vehicle movements in relation to traffic flow parameters. The lengths of each road segment were represented proportional to the actual distances as shown in Figure 2. The model used a 7.5-meter patch so as to not only allow a single vehicle fit into a patch but also allow calculation of vehicle speeds in real units (meters). Thus, each patch represented 7.5 meters in the real world and for simplicity, only one vehicle was allowed per patch. However, while justified by Placzek et al. [18] and Zhang et al. [19], this presented a limitation with the approach in that realistically 
7.5-meter patch could fit more than one car. For the model, this translated into 362 vehicles on each side of the dual carriage road links in the year 2019, 404 in 2020 and growing to 489 in 2021.

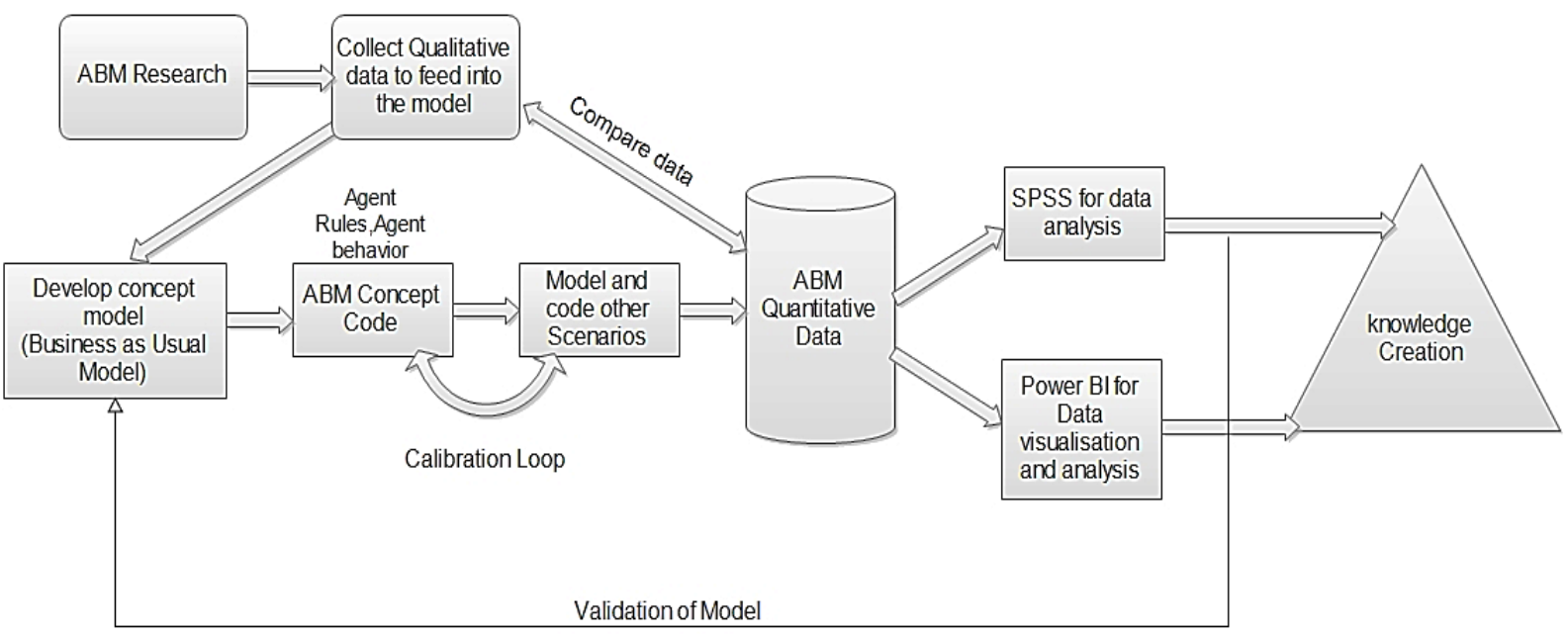

Figure 3: Conceptual model

Zhang et al. describe model calibration as the adjustment of constants and other model parameters in estimated or asserted models in an effort to make the models replicate observed data or otherwise produce more reasonable results [20]. Calibration requires three types of data: inputs, parameters, and outputs [20]. The inputs included the number of vehicles and vehicle population at peak hours in the study area used to calibrate the capacity of the road. At the parameter level the calibration involved adjusting the speed acceleration and deceleration of the vehicles iteratively to conform to the observed data for the junctions. These were thus adjusted to about $35 \mathrm{~km} / \mathrm{hr}, 0.5 \mathrm{~m} / \mathrm{s} 2$ and $0.001 \mathrm{~m} / \mathrm{s}-2$ respectively for the BAU scenario. The calibration also involved controlling the traffic lights and probabilities to turn at junctions for motorists. Finally, the model was validated for sensitivity to small changes in the model, repeatability, and simplicity. After several runs the BAU model was calibrated at $35 \mathrm{~km} / \mathrm{hr}$ as the turtle speed to achieve an equivalence in the times it took a vehicle to exit a particular junction in the real world. Figure 4 presents the calibrated two-dimensional NetLogo world of the turtles (vehicles and traffic lights) and the patches (road network). To quantify the traffic characteristics in the study area, four scenarios were modelled. Scenario 1 (S1) depicts the single-lane BAU traffic situation of 2019 as observed. Building on S1, scenario 2 (S2) models the possibility of dualizing S1 as a possible isolated solution to congestion in 2019, scenario 3 (S3) models a projected dual carriage traffic situation in 2020 and scenario 4 models a projected dual carriage traffic situation in 2021. Scenarios 1 and 2 use actual vehicle population as of 2019 while scenarios 3 and 4 use projected vehicle population for the year 2020 and 2021 as shown in Figure 1. For each scenario, the traffic characteristics generated and tracked included: traffic density, litres lost per kilometre, and vehicle speeds.

\subsection{Theoretical framework}

Motorists in a road network usually have a common goal of minimizing their travel time and choose routes independently to avoid congestion. They can thus, be viewed as participating in a game where individual players have a specific but conflicting goal of minimizing their travel times. Ali et al. states that game theory is a theoretical framework for modelling scenarios in which conflicts of interest exist among competing players in an environment [21]. They further point that it is the science of strategy, or at least the optimal decision-making of independent and competing actors in a strategic setting [21]. Consequently, among many theoretical approaches, game theory has presented feasible solutions to modelling congestion [22]. In such a game, and for any given set of strategies, one for each player, the state for which the players obtain the highest possible utility (i.e. minimum possible travel time) is called the Nash equilibrium [23]. The 
Sibale and Munthali, Adv. J. Grad. Res.; Vol. 10, Issue 1, pp: 3-15, July 2021

Wardrop equilibrium qualifies further in that the high possible utility must have been achieved through distribution of traffic [24]. In both cases, no player can gain any utility by changing the strategy.

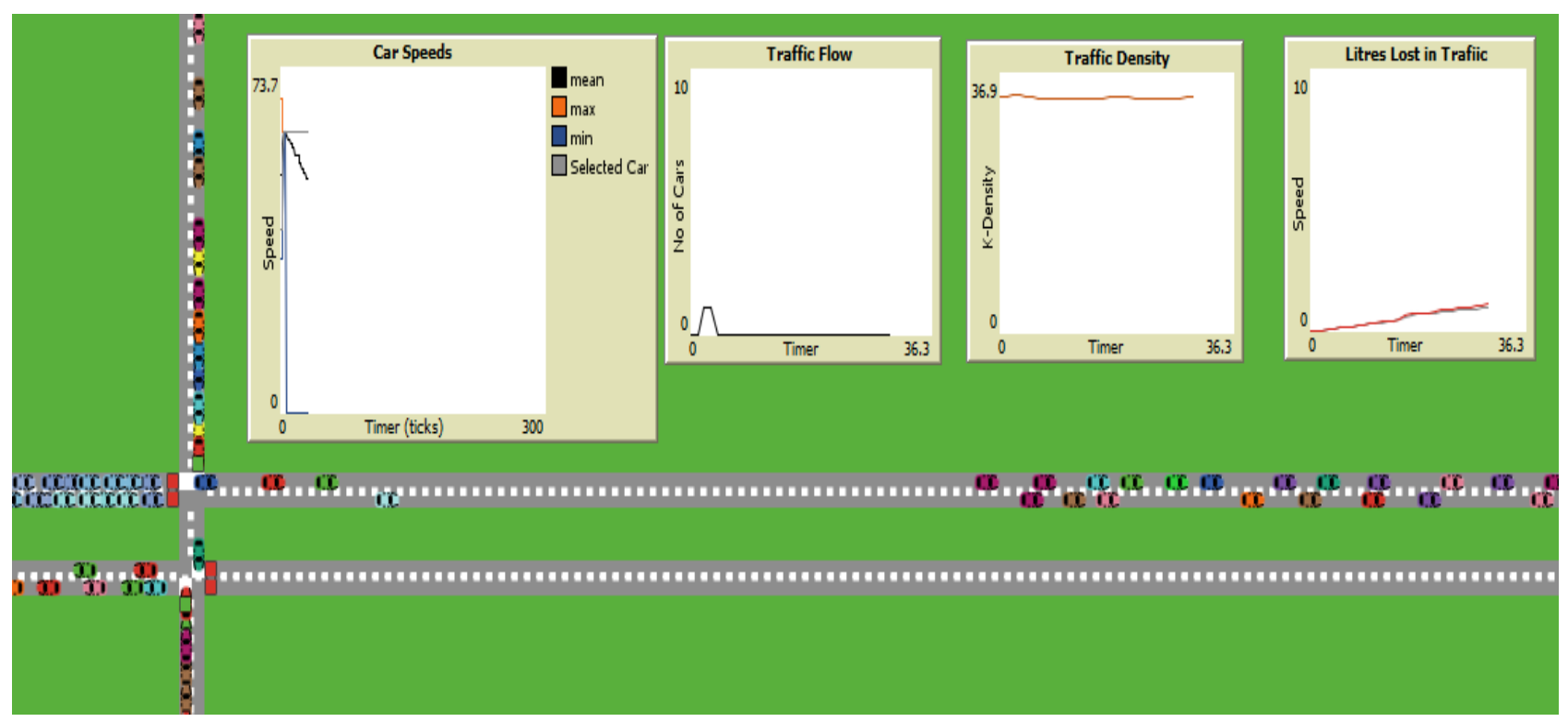

Figure 4: Netlogo worldview

Just like in the real world, Game theory approaches, thus, consider motorists as selfish agents aiming to maximize their own personal utility. There is also an agent representing the traffic system with a utility function based on the efficiency of the traffic network. The goal of game theory approaches is therefore to find the Nash equilibrium for which the traffic system agent's utility is maximized. Upon finding this equilibrium, motorists were then instructed to conform to the strategies in the equilibrium. This was based on the fact that if every driver conformed, each driver's best response to maximize personal gain would be to conform as well.

To implement the model, intersections were signalised as finite controlled Markov chains to optimize the congestion into an avenue as a solution as proposed by Alvarez et al. [25]. Furthermore, each intersection was treated as non-cooperative game where each motorist tried to minimize its queue resulting into Nash's equilibrium as the solution. Optimizing congestion into an avenue as a solution was achieved by controlling the traffic lights at the intersection, implemented as crossing of two one-way streets, within the traffic grid model. Therefore, the street was defined as a finite capacity first-in-first-out buffer or queue such that at any given time $t$, the total number of vehicles in the street is $x_{t}$, the number of vehicles entering it is $\xi_{t}$, and the number of vehicles exiting is $v_{t}$; with the street having a maximum capacity of $n \mid x^{+}$(see Figure 5).

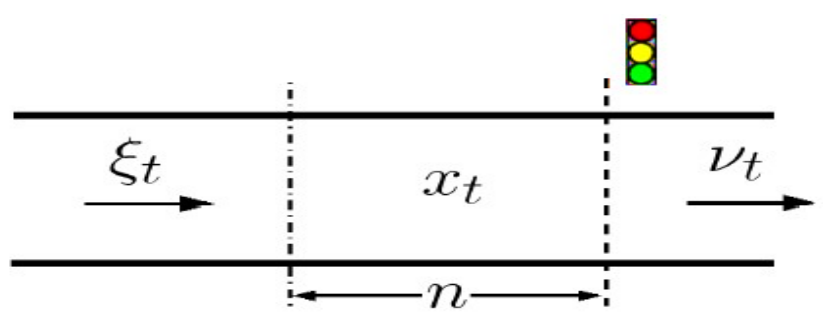

Figure 5: Alvarez Flow Variables (source [25])

Mathematically, the Nash equilibrium is such that, suppose we have $n$ vehicles $1,2,3 \ldots . n$ and each vehicle $i$ has a strategy set $S_{i}$ and members of $S_{i}$ are denoted by $S_{i}$ or $a_{i}$ then each vehicle $i$ will have a utility function $u_{i}: S_{1} x \ldots x S_{n} \rightarrow R$ [26]. Further, if we let $\left(s_{1} \ldots s_{n}\right)$ be a tuple of strategies, one for each vehicle, then $u_{i}\left(s_{1} \ldots s_{n}\right)$ specifies the payoff for vehicle $i$. However, a matrix game $G$ is finite if each 
strategy set $S_{i}$ is finite. Therefore, in the case of two vehicles and a finite game, a game matrix would thus be represented by rows labelled with the strategies for vehicle 1, and columns with the strategies of vehicle 2 such that the matrix entry $M_{i j}$ is the pair of payoffs for the strategy pair $\left(s_{\mathrm{i}}, s_{j}\right)$ [26].

Table 1: Nash Equilibrium matrix illustration

\begin{tabular}{|l|l|l|l|}
\hline \multicolumn{2}{|c|}{} & \multicolumn{2}{|l|}{ Vehicle 2 } \\
\cline { 3 - 4 } \multicolumn{2}{c|}{} & $\mathrm{X}(\mathrm{Go})$ & $\mathrm{Y}$ (Stop) \\
\hline \multirow{2}{*}{ Vehicle 1 } & $\mathrm{X}$ (Go) & $-12,-12$ & $6,-2$ \\
\cline { 2 - 4 } & $\mathrm{Y}$ (stop) & $-2,6$ & $-5,-5$ \\
\hline
\end{tabular}

As shown in Table 1, for each of the four tuples, the first and second numbers correspond to the payoffs to Vehicle 1 and 2 respectively. If both vehicles $G o$, an accident will happen, hence the high negative payoffs for both. If one goes and the other stops, the latter gets a small negative payoff (-2), while the former gets the best possible payoff (6). The traffic lights were therefore programmed in a way to have the best pay off for every vehicle at a junction thus if Vehicle 2 decides to Go, Vehicle 1's better payoff comes from doing Stop $(-2>-12)$. On the other hand, if Vehicle 2 decided to Stop, Vehicle 1 should Go (6>-2). As described by Alvarez et al. the model then computed a green-light and a red-light time using Nash equilibrium, such that at every intersection every vehicle had two options: Go or Stop [25]. Consequently, based on the time instant that two vehicles arrived at the intersection, the traffic lights would inform one to do a Stop, and the other a Go, thereby forcing the whole 'Game' into one of its own Nash equilibria.

\section{$4 \quad$ Results and Discussion}

The validation process of the model involved code inspection and running several simulation tests. This included probability of cars making turns on the junctions, timing of the traffic lights and placement and generation of cars. In each run the model results were compared with the observed ensuring the model was able to achieve real vehicle running times of the observed. For instance, at Bwandilo-Chilambula junction the simulated vehicles took, on average, 37.01 minutes with a standard deviation of 15.57 minutes. This compares to an observed average of 37.06 minutes and standard deviation of 15.34 minutes. Similarly, simulated vehicles averaged 20.3 minutes with a SD of 9.18 minutes, and 58.88 minutes with a SD of 13.95 minutes for Chitukuko junction and Area 18 roundabout, respectively. The former was observed as an average of 20.18 minutes and a SD of 9.11 while the latter was observed as an average of 58.53 minutes with a SD of 13.57 .

As observed and calibrated, during peak hour, S1 informed that a selected motorist entering from Mchinji roundabout will travel at an average speed of $22.60 \mathrm{~km} / \mathrm{hr}$, until it exits the M1 at Chitukuko. If it does not, it continues at an average speed of $22.56 \mathrm{~km} / \mathrm{hr}$ and $25.92 \mathrm{~km} / \mathrm{hr}$ until it exits at Bwandilo-Chilambula M1 junction and Area 18 roundabout, respectively. Furthermore, the motorist spends on average $2.52 \mathrm{~L} / \mathrm{km}$ (MK 2,343.6 or USD3.18), 2.61 L/km (MK 2427.3 or USD3.29), 2.08 1/km (MK 1,934.4 or USD2.63) exiting at Chitukuko, Bwandilo-Chilambula junctions or Area 18 roundabout, respectively.

The rest of the motorists exiting at Chitukuko spent about 2.72 litres/ $\mathrm{km}$ (MK 2,529.6 or USD 3.43) with an average speed of $22.30 \mathrm{~km} / \mathrm{hr}$ ranging from $5.44 \mathrm{~km} / \mathrm{hr}$ to $34.93 \mathrm{~km} / \mathrm{hr}$. Those exiting at BwandiloChilambula spent 2.87 litres/ $\mathrm{km}$ (MK 2,669.1 or USD 3.62), an average speed of $23.65 \mathrm{~km} / \mathrm{hr}$ ranging from $6.75 \mathrm{~km} / \mathrm{hr}$ to $34.95 \mathrm{~km} / \mathrm{hr}$. Similarly, for those exiting at Area 18 roundabout, they spent 2.07 litres $/ \mathrm{km}$ (MK 1,925.1 or USD2.61) with an average mean speed of $27.06 \mathrm{~km} / \mathrm{hr}$ ranging from $9.46 \mathrm{~km} / \mathrm{hr}$ to 34.95 $\mathrm{km} / \mathrm{hr}$. In terms of traffic density, for the stretches up to Chitukuko, Bwandilo-Chilambula and Area 18 roundabout, the model informed 72, 65 and 41 vehicles $/ \mathrm{km}$ of traffic density, respectively. For $\mathrm{S} 1$, as shown in figure 4, the traffic situation is such that the traffic parameters generally improve as one moves from Chitukuko, Bwandilo-Chilambula all the way to Area 18 roundabout for both tracked vehicle and the rest of the vehicles (see Figure 6). 


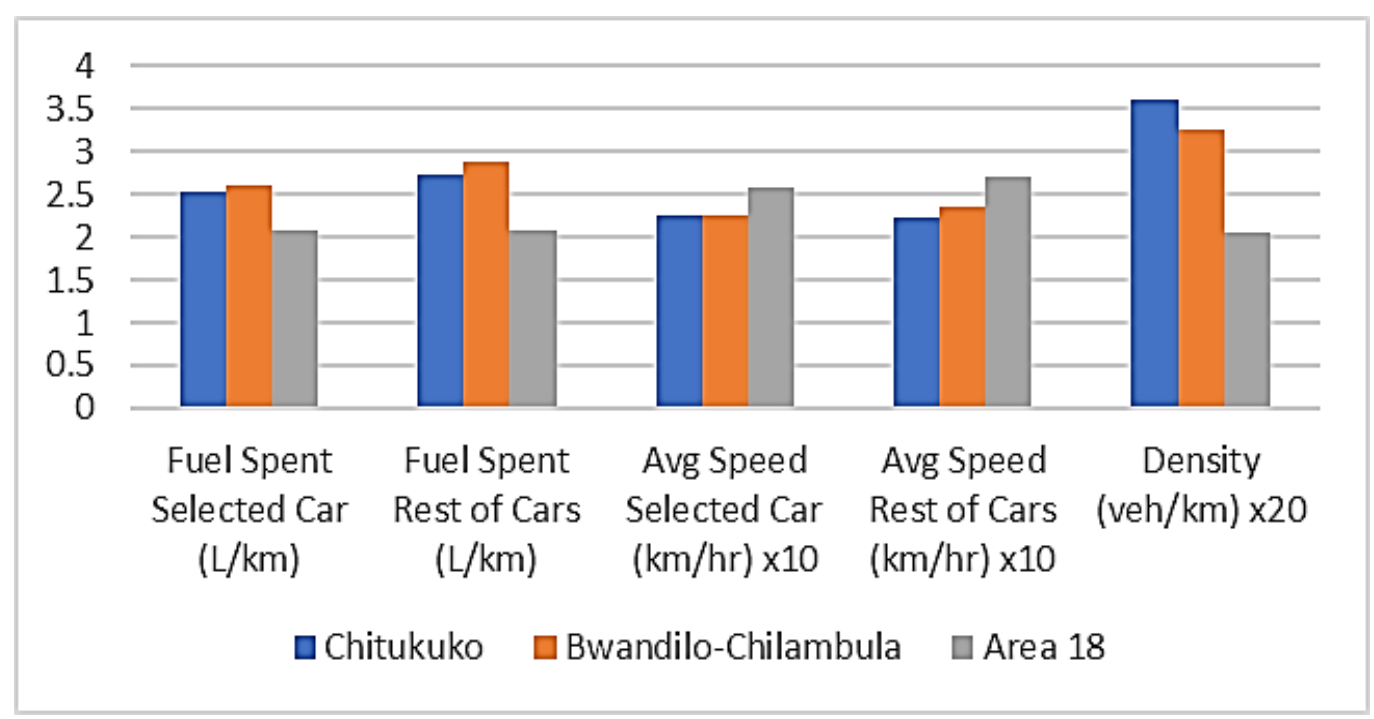

Figure 6: Traffic parameters in $S 1$

\subsection{Dualizing the M1}

Upon dualizing the M1 in the study area, S2 informed that the average speed of a selected vehicle exiting at Chitukuko increased to $41.54 \mathrm{~km} / \mathrm{hr}$ while the traffic density declined to 54.42 vehicles $/ \mathrm{km}$. Furthermore, S2 informs that the motorist saved MK 604.5 (USD 0.82) spending 1.87 litres $/ \mathrm{km}$. At Bwandilo-Chilambula junction, the average speed for a selected vehicle increased to $47.43 \mathrm{~km} / \mathrm{hr}$, the traffic density declined to 39.74 vehicles $/ \mathrm{km}$, fuel expenditure reduced to 2.27 litres $/ \mathrm{km}$ (MK 2,111.1 or USD 2.87) and the motorist saved MK 316.2 (USD 0.43). For the rest of the vehicles, for those exiting at Chitukuko, S2 informed that they spend an average of 2.32 litres $/ \mathrm{km}$ (MK 2,157.6 or USD 2.93) at an increased average speed of 42.78 $\mathrm{km} / \mathrm{hr}$ whilst saving an average of MK 372 (USD 0.5). For those exiting at Bwandilo-Chilambula junction, S2 informed that the vehicles spend an average of 2.5 litres (MK 2,325 or USD 3.16) driving at an average speed of $46.16 \mathrm{~km} / \mathrm{hr}$ and managed to save MK 344.1 (USD 0.47). The study also tracked the amount of time spent by motorist in S1 compared to S2. The model informs that on average at Chitukuko, Bwandilo and Area 18 roundabout exit road junctions, motorist spend 8.38 minutes, 15.62 minutes and 18.58 minutes in S2 as compared to 20.3 minutes, 37.1 minutes and 58.88 minutes respectively in S1.

A simulation for all the junctions was set as per the observed time of 2 hours the vehicles took to enter the Mchinji roundabout on one end and exit the furthest junction at Area 18 roundabout at peak hours between 5 to $7 \mathrm{pm}$. In S1 vehicles entering Mchinji roundabout took an average of 1 hour 58 minutes until they exit Area 18 roundabout while in S2 they took on average 49 minutes. S1 further informed that vehicles lose fuel at a rate of 13.41 litres $/ \mathrm{km}$ with a mean speed of $34.41 \mathrm{~km} / \mathrm{hr}$. In S2, these generally improved with fuel losses of 8.62 litres $/ \mathrm{km}$, and mean speed of $51.96 \mathrm{~km} / \mathrm{hr}$.

Table 2: S1 and S2 Simulation Data

\begin{tabular}{|c|c|c|c|c|c|c|c|c|}
\hline & \multicolumn{2}{|l|}{ Daily } & \multicolumn{2}{|l|}{ Weekly } & \multicolumn{2}{|c|}{ Monthly } & \multicolumn{2}{|l|}{ Yearly } \\
\hline & S1 & S2 & S1 & S2 & S1 & S2 & S1 & S2 \\
\hline Fuel (litres) & 49.18 & 31.61 & 245.9 & 158.05 & 983.6 & 632.2 & $11,803.2$ & $7,586.4$ \\
\hline Cost (MK) & $45,737.4$ & $29,397.3$ & 228,687 & $146,986.5$ & 914,748 & 587,946 & $10,976,976$ & $7,055,352$ \\
\hline $\begin{array}{l}\text { Time spent } \\
\text { (Minutes) }\end{array}$ & 118.00 & 49.00 & 590.00 & 245.00 & $2,360.00$ & 980.00 & $28,320.00$ & $11,520.00$ \\
\hline
\end{tabular}

Table 2 presents the aggregated traffic parameters of fuel spent in litres and kwacha and the time spent by motorists in S1 and S2. Daily, the dual carriage (S2) informs that motorists, would save 69 minutes and 17.38 litres of fuel equivalent to a saving of MK 16,340.10 (USD 22.22). These savings accumulate to 345 and 87.85; and 1,380 and 351.4 of minutes and litres weekly and monthly respectively. This translates to monetary savings 
of MK81,700.5 (USD 111.12) and MK326,802 (USD 444.49) weekly and monthly respectively. Annually the simulation informs that with the introduction of dual carriage in S2, commuters would save 280 hours (almost 12 days) and 4,216.8 litres of fuel translating to a monetary saving of MK 3,921,624.00 (USD 5,333.84).

\subsection{0 and 2021 projected dual carriage capacity}

Given the projected vehicle population in Figure 1 we then run a predictive analysis for the year 2020 and 2021 simulating each vehicle until it exited the M1 Junctions. The quantified results are presented in Figure 7 starting from daily, weekly, monthly up to yearly estimates. The model, thus, informed that vehicles entering Mchinji roundabout would take on average 74 and 104 minutes to exit the dual carriage in 2020 and 2021 respectively. In terms of fuel, the consumption increases from 31.63 litres in 2019 to 39.32 and 72.42 litres for all motorists in 2020 and 2021 translating into consumption rates of 10.72 and 19.75 litres $/ \mathrm{km}$ respectively. In 2020 the vehicle speed in the study area averages $50.43 \mathrm{~km} / \mathrm{hr}$ with individual speeds ranging between 17.24 to $59.88 \mathrm{~km} / \mathrm{hr}$. The speeds average $43.21 \mathrm{~km} / \mathrm{hr}$ with a range between 15.14 to $59.81 \mathrm{~km} / \mathrm{hr}$ in 2021 .

Figure 7 shows that increase in the number of vehicles in the study area, with an isolated dual lane intervention, will reduce travel times in the first year followed by an increment in travel times in the following years. Again, the dual carriage will increase vehicle speeds in the first year followed by reduced speeds in the following years and cost commuters more money on fuel. The results of the simulation already suggest the BAU scenario of the single lane in 2019 to be attained as early as 2021 with a dual lane.

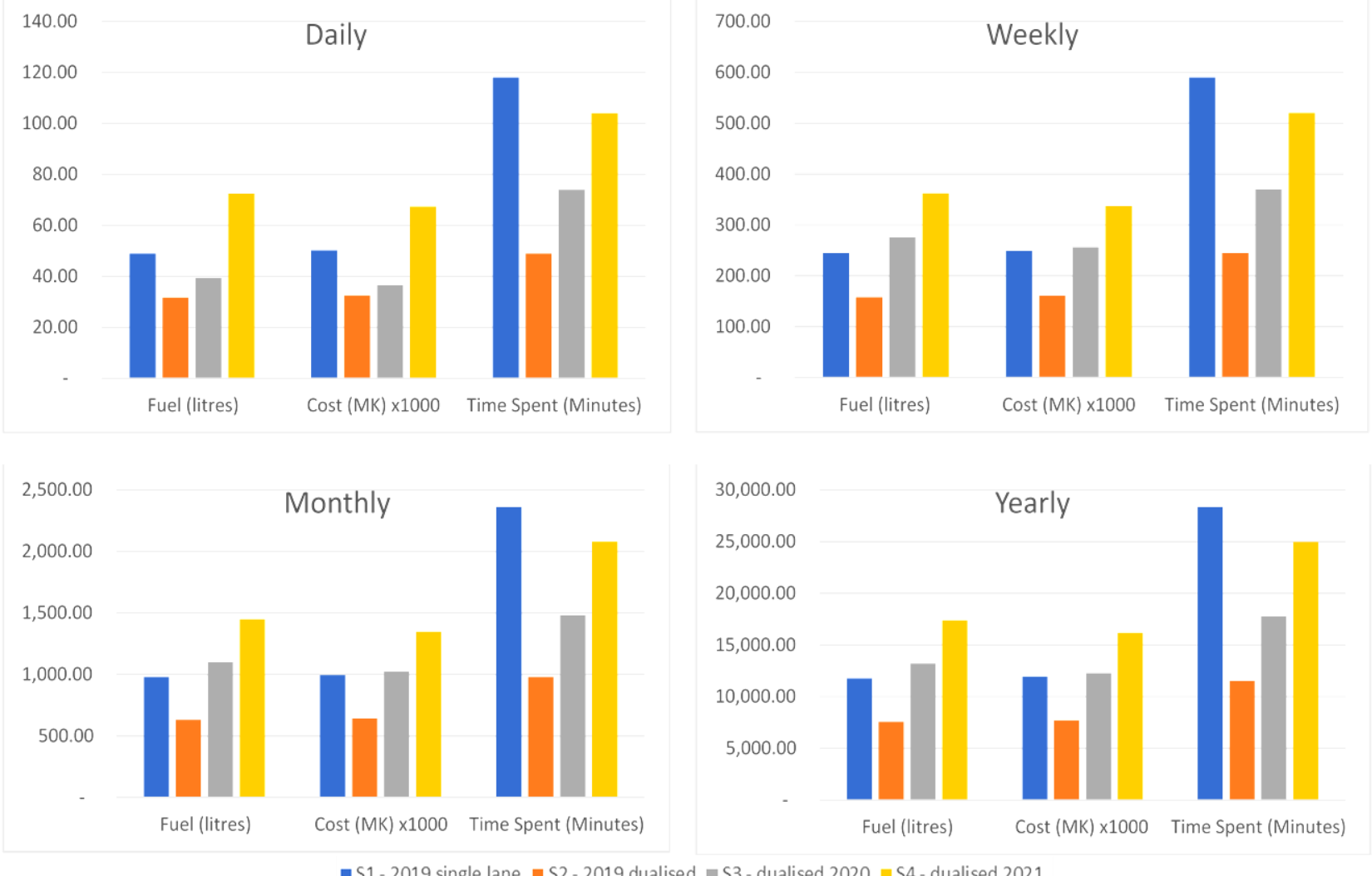

Figure 7: Dual carriage model data Comparison

Specifically, the results indicate that motorists save 4,216.6 litres (MK 3,921,438 or USD 5,333.59) in S2 but spend more money on fuel in S3 (MK 5,231,361 or USD 7,115.23) and S4 (MK 9,108,792 or USD 12,388.96). The results, while counterintuitive, agree with Jupp [27] who reported that the introduction of a dual carriage of the A428 between Cambridgeshire and Bedfordshire in England would save commuters up to 90 minutes. Milam [28] found out that for every 1 percent increase in highway capacity, traffic 
increases 0.29 to 1.1 percent in the long term (about five years out), and up to 0.68 percent in the short term (one or two years). Thus, building a highway or expanding a road segment essentially create additional traffic, which in turn causes them to become congested all over again leading to a phenomenon known as induced demand. Furthermore, Speck stipulates that for every new kilometre of roadway that is built becomes $40 \%$ filled up with new trips almost immediately, and 100\% full within four years and sometimes much earlier [29].

Leigh highlights that congestion-reduction measures can be thought of as falling into two categories: temporary and virtuous [30]. Temporary measures free up road capacity that is soon filled by induced demand as people adapt their lifestyles to prevailing road conditions. On the other hand, virtuous measures start a feedback loop that induces more and more people to make a modal shift away from driving. The results here speak more to the former especially for developing countries, such that, in the study area, construction of a dual carriage road will only solve traffic congestion for practically just the first 2 years. This is evidenced by the increase in litres and time spent on the road from the second year.

\section{Conclusion}

The study has quantified the macroscopic traffic characteristics of density, average speed and fuel consumption both in terms of litres and cost for M1 stretch in Lilongwe. Except for the time spent on the road, by 2021 the fuel consumed, and money spent in the dual carriage would have exceeded the fuel and money spent on the same in 2019 in the single lane. As such while the research showed that turning a single lane into a dual carriage would increase travel speeds, reduce traffic density thereby saving time and money for motorists in Lilongwe, this would only be for a short period. By 2021 motorists in the study area would have been spending just as much as in the single lane situation. The research therefore informs that a dual carriage road in the study area would not be a sustainable solution to ease traffic congestion especially when operationalized in isolation as per the simulation. The research therefore recommends a dual carriage in the study area only if it will either buy time or lay the foundations for more radical interventions. It is thus imperative that dualization should be done virtuously with supporting interventions that include introducing a public transportation system and/or expanding the connecting supporting roads. The former would provide a more convenient and cheaper option that can increase patronage and encourage more motorists to shift away from self-driving and thereby free up the roads.

\section{Declarations}

\subsection{Study Limitations}

The limitations of the model were in terms of the vehicle length which literature has assigned to $7.5 \mathrm{~m}$ since a vehicle fits in a $7.5 \mathrm{~m}$ patch in a CA model. The average length of a vehicle with an engine of less than $1600 \mathrm{cc}$ is $4.5 \mathrm{~m}$ but vehicles are longer than $4.5 \mathrm{~m}$ in length with engines of over $1600 \mathrm{cc}$. It would have therefore been ideal if a single patch would fit 1.6 vehicles. Despite this limitation the model was calibrated using real world traffic parameters and was validated by its ability to replicate real world traffic patterns hence making it credible. The second limitation was the assumption that in the 3 years of the simulation the capacity of the feeder roads around the study area would remain the same. This was largely to achieve simplicity of the simulation both computationally and in comprehension.

\subsection{Competing Interests}

The authors declare that they have no known competing financial interests or personal relationships that could have appeared to influence the work reported in this paper.

\subsection{Publisher's Note}

AIJR remains neutral with regard to jurisdictional claims in published maps and institutional affiliations. 


\section{How to Cite this Article:}

K. B. Sibale and K. G. . Munthali, "Analysing Road Traffic Situation in Lilongwe: An Agent Based Modelling (ABM) Approach”, Adv. J. Grad. Res., vol. 10, no. 1, pp. 3-15, Mar. 2021.

\section{References}

[1] W.-X. Wang, R.-J. Guo, and J. Yu, "Research on road traffic congestion index based on comprehensive parameters: Taking Dalian city as an example," Advances in Mechanical Engineering, vol. 10, no. 6, p. 1687814018781482, Jun. 2018, doi: $10.1177 / 1687814018781482$.

[2] N. Tsanakas, J. Ekström, and J. Olstam, "Estimating Emissions from Static Traffic Models: Problems and Solutions," Journal of Advanced Transportation, vol. 2020, p. 5401792, Feb. 2020, doi: 10.1155/2020/5401792.

[3] T. Reed, "INRIX Global Traffic Scorecard,” 2019, [Online]. Available: https://trid.trb.org/view/1456836.

[4] D. Transport, "Department Of Transport Vote NO. 35 Annual Report 2018/2019 Financial Year," 35. [Online]. Available: https://www.gov.za.

[5] M. N. S. Office, 2018 Population and Housing Census: Main Report. National Statistical Office, 2019.

[6] V. Shikhin, "Introductory Chapter: Major Automatic Control Challenges in Multi-Agent Systems," Multi-Agent Systems - Control Spectrum, Jan. 2019, doi: 10.5772/intechopen.83450.

[7] K. J. Murphy, S. Ciuti, and A. Kane, "An introduction to agent-based models as an accessible surrogate to field-based research and teaching," Ecology and Evolution, vol. 10, no. 22, pp. 12482-12498, 2020, doi: https://doi.org/10.1002/ece3.6848.

[8] H. Wang, J. Zhang, and W. Zeng, "Intelligent simulation of aquatic environment economic policy coupled ABM and SD models," Science of The Total Environment, vol. 618, pp. 1160-1172, Mar. 2018, doi: 10.1016/j.scitotenv.2017.09.184.

[9] K. Kuusemäe, M. von Thene, T. Lange, E.K. Rasmussen, M. Pothoff, A.I. Sousa, and M.R. Findt, "Agent Based Modelling (ABM) of eelgrass (Zostera marina) seedbank dynamics in a shallow Danish estuary," Ecological Modelling, vol. 371, pp. 60-75, Mar. 2018, doi: 10.1016/j.ecolmodel.2018.01.001.

[10] K. G. Munthali, "Modelling deforestation in dzalanyama forest reserve, Lilongwe, Malawi: using multi-agent simulation approach," Un published Phd Thesis-the University of Tsukuba, 2013.

[11] E. Lindkvist, N. Wijermans, T.M. Daw, B. Gonzalez-Mon, A. Giron-NAva, A.F> Johnson, I. van Putten, X. Basurto, and M. Schuter, "Navigating Complexities: Agent-Based Modeling to Support Research, Governance, and Management in Small-Scale Fisheries," Front. Mar. Sci., vol. 6, 2020, doi: 10.3389/fmars.2019.00733.

[12] M. Schlüter, L.J. Haider, S.J. Lade, E. Lindkvist, R. Martin, K. Orach, N. Wijermans, and C. Folke, "Capturing emergent phenomena in social-ecological systems: an analytical framework," Ecology and Society, vol. 24, no. 3, Aug. 2019, doi: 10.5751/ES-11012240311.

[13] K. G. Munthali and Y. Murayama, "Modeling deforestation in Dzalanyama Forest Reserve, Lilongwe, Malawi: a multi-agent simulation approach," GeoJournal, vol. 80, no. 5, pp. 743-757, Oct. 2015, doi: 10.1007/s10708-014-9592-4.

[14] D. F. Adamatti, Multi-Agent-Based Simulations Applied to Biological and Environmental Systems. Hershey, PA: Information Science Reference - Imprint of: IGI Publishing, 2016.

[15] U. Wilensky, "The NetLogo 6.1.1 User Manual,” https://ccl.northwestern.edu/netlogo/docs/, pp. 1-449, 2019, [Online]. Available: https://ccl.northwestern.edu/netlogo/docs/.

[16] Z. H. Khan and T. A. Gulliver, "A macroscopic traffic model for traffic flow harmonization," European Transport Research Review, vol. 10, no. 2, p. 30, Jun. 2018, doi: 10.1186/s12544-018-0291-y.

[17] D. Uribe, L. Lugo, and E. Cuan, "Deep Analysis of a Basic Traffic Model," Res. Comput. Sci., 2016, doi: 10.13053/rcs-118-1-4.

[18] M. Bernas, B. Płaczek, and J. Smyła, "A Neuroevolutionary Approach to Controlling Traffic Signals Based on Data from Sensor Network,” Sensors, vol. 19, no. 8, Art. no. 8, Jan. 2019, doi: 10.3390/s19081776.

[19] B. Płaczek, M. Bernas, and M. Cholewa, "A Credibility Score Algorithm for Malicious Data Detection in Urban Vehicular Networks," Information, vol. 11, no. 11, Art. no. 11, Nov. 2020, doi: 10.3390/info11110496.

[20] Y. Zhang, Z. Li, and Y. Zhang, "Validation and Calibration of an Agent-Based Model: A Surrogate Approach," Discrete Dynamics in Nature and Society, vol. 2020, pp. 1-9, Jan. 2020, doi: 10.1155/2020/6946370.

[21] Y. Ali, Z. Zheng, Md. M. Haque, and M. Wang, "A Game Theory-based Approach for Modelling Mandatory Lane-Changing Behaviour in a Connected Environment," Transportation Research Part C Emerging Technologies, vol. 106, pp. 220-242, Jul. 2019, doi: 10.1016/j.trc.2019.07.011.

[22] A. Navon et al., "Applications of Game Theory to Design and Operation of Modern Power Systems: A Comprehensive Review," Energies, vol. 13, no. 15, Art. no. 15, Jan. 2020, doi: 10.3390/en13153982.

[23] H. Asienkiewicz and $€$. Balbus, "Existence of Nash equilibria in stochastic games of resource extraction with risk-sensitive players," TOP, vol. 27, no. 3, pp. 502-518, Oct. 2019, doi: 10.1007/s11750-019-00516-2.

[24] S. Galib, S. A. Forhad, G. M. M. Bashir, and B. Hossain, "Application of Game Theory to Road Traffic Optimisation," p. 5, 2016, [Online]. Available: https://www.ijcsmc.com/docs/papers/March2016/V5I3201605.pdf.

[25] I. Alvarez, A. Poznyak, and A. Malo, "Urban traffic control problem a game theory approach," in 2008 47th IEEE Conference on Decision and Control, Dec. 2008, pp. 2168-2172, doi: 10.1109/CDC.2008.4739461.

[26] S. Sun and N. Sun, Management Game Theory. Springer Singapore, 2018. 
Sibale and Munthali, Adv. J. Grad. Res.; Vol. 10, Issue 1, pp: 3-15, July 2021

[27] E. Jupp, "Replacement for notorious A428 'Black Cat' roundabout gets public support," Motoring Research, Feb. 10, 2020. https://www.motoringresearch.com/car-news/black-cat-roundabout-replacement-public-support/ (accessed Jan. 13, 2021).

[28] R. T. Milam, M. Birnbaum, C. Ganson, S. Handy, and J. Walters, "Closing the Induced Vehicle Travel Gap Between Research and Practice:," Transportation Research Record, Jan. 2017, doi: 10.3141/2653-02.

[29] J. Speck, "Understand Induced Demand," in Walkable City Rules: 101 Steps to Making Better Places, J. Speck, Ed. Washington, DC: Island Press/Center for Resource Economics, 2018, pp. 64-65.

[30] E. Leigh, "Reducing Traffic Congestion and Pollution in Urban Areas," Smarter Cambridge Transport, Dec. 12, 2016. https://www.smartertransport.uk/smarter-cambridge-transport-urban-congestion-enquiry/ (accessed Oct. 19, 2020).

Publish your books with AIJR publisher-

- Publish with ISBN and DOI.

- Publish Thesis/Dissertation as Monograph.

- Publish Book Monograph.

- $\quad$ Publish Edited Volume/ Book.

- $\quad$ Publish Conference Proceedings

- Retain full copyright of your books.

Submit your manuscript at books.aijr.org
Publish your research article in AIJR journals-

- Online Submission and Tracking

- $\quad$ Peer-Reviewed

- Rapid decision

- Immediate Publication after acceptance

- Articles freely available online

- Retain full copyright of your article.

Submit your article at journals.aijr.org 